Methods Rheumatologists from seven hospitals completed an audit form on consecutive patients in rheumatology outpatient departments over six months. Information on details of all orthopaedic procedures, waiting times, inpatient stays, complications, concurrent rheumatological drug therapies was obtained from medical records and from patients themselves (inflammatory joint disease was primary diagnosis in $81 \%$ ).

Results A total of 406 orthopaedic operations were performed in 293 patients, 106 total knee replacements (26\%), 71 total hip replacements (17.5\%), 48 wrist/hand joint operations (12\%), 27 forefoot arthroplasties (6.7\%), 15 shoulder replacements (3.7\%), 14 elbow replacements (3.4\%), 12 ankle fusions (3\%) and the remainder miscellaneous.

The main post operative complications which resulted in increased lenght of inpatient stay were wound sepsis (17), chest infection (4), deep vein thrombosis (4) joint dislocation/fracture (3). Main second line drugs were sulphasalzine (65) and methotrexate (58) and steroids were used by 39 patients. Figures will show differences between centres for waiting times (median 9 months) and inpatient stays (median 7 days).

Conclusion Marked variations in waiting times could be identified to specific local difficulties which are being addressed. Cessation or changes in second line drugs were uncommon and created only short lasting problems, but need to be reviewed regularly.

\section{THU0201 ABILITY OF THE LABORATORY TESTS TO PREDICT RHEUMATOID ARTHRITIS IN PATIENTS WITH EARLY ARTHRITIS}

A Saraux, JM Berthelot, G Chales, C Le Henaff, JY Mary, JB Thorel, S Hoang, M Dueymes, V Devauchelle, D Baron, P Le Goff, P Youinou. Rheumatology, Brest University Medical School, Brest, France

10.1136/annrheumdis-2001.1103

\section{Background}

Objectives To determine the diagnostic value in early rheumatoid arthritis (RA) of various laboratory tests used alone or in combination.

Methods A cohort of 270 patients with early arthritis was constituted between 1995 and 1997 in seven hospitals in Brittany (France). Each patients underwent at first visit a standardised examination, laboratory tests [rheumatoid factors (RF), the functionnal affinity of IgM-rheumatoid factors, antiperinuclear factor, IgG, IgM and IgA antikeratin antibody (AKA), antiRA33 antibody, antinuclear antibodies, ELISA analysis of IgG glycosylation, circulating immune complexes, $\operatorname{IgG} 1, \operatorname{IgG} 2, \operatorname{IgG} 3$, and $\operatorname{IgG}$ 4, and HLA AB DR typing], and radiographs. They were examined in the same way at six-month intervals until their last visit between June and December 1999, when the diagnosis of RA was made by a panel of five rheumatologists. Ninety-eight (38\%) patients were considered as having RA at their final visit. The ability of each test as measured at the initial visit to discriminate between RA and non RA patients was evaluated through sensitivity and specificity. Optimal cutoff for continuous test was derived from Received Operating Characteristic curve. Multiple logistic regression was used to select combination of laboratory tests able to discriminate between RA and non RA patients and the diagnostic value of these combination was evaluated through sensitivity and specificity.

Results The performance of the combinations using either the pair with the best diagnostic value combined with a third selected laboratory test or multiple logistic regression demonstrated that high levels of IgM RF by ELISA, IgG AKA, and latex test had the strongest association to RA.

Conclusion IgM-RF by ELISA, IgG-AKA, and the latex test are the best laboratory tests for discriminating between patients with and without RA. The other biological tests did not improve the diagnostic value.

\section{THU0202 PATTERN OF RADIOGRAPHIC DAMAGE OF THE HAND JOINTS IN RHEUMATOID ARTHRITIS: A STUDY OF 193 PATIENTS}

LS Ines, P Reis, MJ Santos, M Alexandre, C Silva, A Branha, A Figueiredo, D Nour, JA Da Silva, A Malcata, A Porto. Rheumatology Department, University Hospital of Coimbra, Coimbra, Portugal

\subsection{6/annrheumdis-2001.1104}

Background Metacarpophalangeal (MCP) and proximal interphalangeal (PIP) joints of the hands are some of the most frequently involved areas in rheumatoid arthritis (RA). However, observational data suggest that differences may exist between different fingers.

Objectives To evaluate the pattern of radiographic damage of the wrists and small joints of the hands in RA patients.

Methods Cross-sectional study of 193 RA patients, fulfilling the 1987 ACR criteria (female $=168$ [87\%], male $=25$ [13\%]; mean age $=57.0 \pm 11.7$ years; mean disease duration $=13.4$ \pm 8.1 years; RF positive $=72 \%$ ). They attended consecutively our hospital-based outpatient rheumatology clinic. Radiographs of the hands were obtained from all patients. Wrists, MCP, PIP and distal interphalangeal joints (DIP) were scored using Larsen's method. All radiographs were evaluated by a single reader in a blinded fashion. The intrarreader concordance rate was $>0.82$ for all joints.

Results Mean Larsen scores were $2.25 \pm 1.54$ for wrists, $1.70 \pm$ 1.49 for MCPs, $1.29 \pm 1.19$ for PIPs and $0.84 \pm 0.74$ for DIPs. There were erosive changes in $62.7 \%$ of the wrists, $39.0 \%$ of the MCPs, $27.4 \%$ of the first finger interphalangeals, $20.8 \%$ of the PIPs and $10.3 \%$ of the DIPs. Mean scores for each joint area and for each finger are presented in the Table 1 below.

\begin{tabular}{llllll}
\multicolumn{6}{l}{ Abstract THU0202 Table 1} \\
\hline & Finger 1 & Finger $\mathbf{2}$ & Finger $\mathbf{3}$ & Finger $\mathbf{4}$ & Finger $\mathbf{5}$ \\
\hline MCP & $1.73 \pm 1.36$ & $1.91 \pm 1.60$ & $1.74 \pm 1.49$ & $1.53 \pm 1.37$ & $1.62 \pm 1.46$ \\
PIP & $1.37 \pm 1.20$ & $1.53 \pm 1.35$ & $1.20 \pm 1.16$ & $1.20 \pm 1.12$ & $1.15 \pm 1.10$ \\
DIP & N/A & $0.81 \pm 0.79$ & $0.92 \pm 0.84$ & $0.82 \pm 0.69$ & $0.82 \pm 0.66$ \\
\hline
\end{tabular}

Conclusion Mean radiographic damage increases from DIPs to proximal joints up to the wrist. There are also differences of the damage of each joint area between fingers. Functional and mechanical factors may contribute to these differences.

\section{THU0203 INCIDENCE OF CHLOROQUINE RETINOPAHY IN RHEUMATOID ARTHRITIS PATIENTS}

1J Gonzalez-Dominguez, ${ }^{2} \mathrm{M}$ Santos, ${ }^{1} \mathrm{~A}$ Escudero, ${ }^{1} \mathrm{~A}$ Cisnal, ${ }^{1} \mathrm{M}$ Romero, ${ }^{1} \mathrm{~V}$ Perez, ${ }^{1} \mathrm{MD}$ Lopez, ${ }^{1} \mathrm{MA}$ Caracuel, ${ }^{1} \mathrm{FG}$ Martinez, ${ }^{2} \mathrm{JM}$ Gallardo, ${ }^{1} \mathrm{E}$ Collantes. ${ }^{1}$ Rheumatology; ${ }^{2}$ Ophthalmology, Hospital Universitario Reina Sofia, Cordoba, Spain

10.1136/annrheumdis-2001.1105 


\section{Background}

Objectives To evaluate risk of chloroquine (CQ) retinal toxicity in rheumatoid arthritis (RA) patients.

Methods Retrospective case-control study of RA patients attended from 1987 to 1999 in our Rheumatology Service. One hundred and fifty RA patients (120 females (F) and 30 males (M) with a mean age of $64 \pm 40$ years, who lives in the same geographical area, received daily CQ dosage of $250 \mathrm{mg}$. Ophthalmologic examination was carried out exam previous CQ treatment and toxicity routine ophthalmic screening every 6 months include fundus, central campimetry and tests of colours Farnsworth D-28. After identification of central visual field alteration and/or fundus CQ treatment was stopped.

Results Eight patients (5.3\%), 8 females with mean age of 63.6 \pm 11.4 years were identify with CQ retinopathy. Six patients (5F and $1 \mathrm{M}$ ) 4\% with visual colour defects without CQ retinopathy were detected. Rheumatoid factor (RF) was present in $75 \%$ of retinopathy CQ patients (group A) vs. $72.6 \%$ in the patients without retinopathy (group B). The duration of treatment and cumulative total dose of CQ was in group A $3.4 \pm 2.1$ yrs. and $193.7 \pm 104.4$ gm vs. $3.3 \pm 2.6$ yrs. and $184 \pm 125.9 \mathrm{gm}$ in group B group.

Conclusion The CQ retinal toxicity was of 5.3\%, not related with age, rheumatoid factor, duration of treatment and cumulative total dose.

\section{THU0204 THE (UN)COUPLING OF INFLAMMATION AND DESTRUCTION IN PATIENTS TREATED WITH RHIL-1RA}

${ }^{1} \mathrm{AM}$ Van Gestel, ${ }^{1} \mathrm{PL}$ Van Riel, ${ }^{2} \mathrm{C}$ Lindsay, ${ }^{2} \mathrm{JM}$ Robinson. ${ }^{1}$ Department of Rheumatology, University Medical Centre Nijmegen, Nijmegen, The Netherlands; ${ }^{2}$ Amgen, Thousand Oaks, USA

\subsection{6/annrheumdis-2001.1106}

Background Previous studies have shown that recombinant human interleukin-1 receptor antagonist (rhIL-1ra) has an effect on RA disease activity and on the progression of radiographic damage. In animal models an uncoupling between joint inflammation and joint destruction is found with rhIL-1ra. We hypothesised that in case of uncoupling the association found between these disease aspects would be different for patients treated with rhIL-1ra versus placebo.

Objectives To study the coupling between disease activity and radiographic damage in a 24 -week placebo controlled trial of rhIL-1ra in 472 RA patients.

Methods Since no clear dose-response relation has been shown for the 3 active groups $(30,75,150 \mathrm{mg} / \mathrm{d})$, these groups were combined for the analyses.

Models were made to explain the Larsen progression score (LPS) by treatment group (TG), EULAR response (EUL), and TG*EUL interaction term. In a different model the EUL was replaced with the endpoint DAS28.

Results At 24 weeks LPS was partly explained by TG $(\mathrm{p}=0.02)$ but not by EUL. Exchanging EUL for DAS28, LPS was partly explained by DAS28 $(\mathrm{p}<0.001)$ and TG*DAS28 ( $\mathrm{p}=0.02)$. The higher the DAS28 the higher the LPS, and this was more pronounced in the placebo group.

Conclusion At 24 weeks the association between x-ray progression and inflammation is more pronounced in the placebo group, suggesting an uncoupling with active rhIL-1ra treatment. Further data analyses, including the 24 week extension of the trial, might confirm these findings.

\section{Abstract THU0204 Table 1}

\begin{tabular}{lll}
\hline & rhlL-1ra & Placebo \\
\hline Good response & $2.94(6.7) n=17$ & $-4.33(11.1) n=3$ \\
Moderate response & $3.47(7.8) n=94$ & $5.22(13.9) n=27$ \\
Non response & $4.49(9.2) n=136$ & $8.52(9.8) n=48$ \\
\hline
\end{tabular}

Mean (sd) Larsen progression score week $0-24$.

\section{REFERENCE}

1 Breshnihan B, Alvaro-Gracia JM, Cobby M, et al. Treatment of rheumatoid arthritis with recombinant human interleukin-1 receptor antagonist. Arthritis Rheum. 1998;41:2196-204

\section{THU0205 COMPARISON OF SELF-REPORTING MEASURES OF FUNCTIONAL DISABILITY AND CLINICAL VARIABLES IN RHEUMATOID ARTHRITIS IN A TURKISH POPULATION}

${ }^{1} \mathrm{P}$ Borman, ${ }^{1} \mathrm{~L}$ Yilmaz, ${ }^{1} \mathrm{H}$ Gunduz, ${ }^{2} \mathrm{~N}$ Barca, ${ }^{3} \mathrm{MT}$ Duruoz. ${ }^{1}$ Physical Medicine and Rehabilitation; ${ }^{2}$ Radiology Department, Numune Education and Research Hospital, Ankara; ${ }^{3}$ Physical Medicine and Rehabilitation, Celal Bayar University Medical School, Manisa, Turkey

10.1136/annrheumdis-2001.1107

\section{Background}

Objectives To assess the relationship between the clinical variables and the functional disability of patients with rheumatoid arthritis (RA) in a Turkish population and to determine whether simple self-reporting questionnaires provide information as accurate as traditional measurements of RA.

Methods Subjects with rheumatoid arthritis according to ACR criteria were recruited consecutively. Clinical and radiological parameters were correlated with Turkish versions of the disability scales (HAQ, AIMS and Duruöz?s Hand Index-DHI) to obtain the relationship between disease activity and the functional disability status of each patient. Pearson?s correlation coefficient and Student?s t test were used to assess the relationship between two quantitative variables and two groups (early and established RA), respectively. $\mathrm{p}<0.05$ was accepted as significant.

Results Fifty patients (40 women) with a mean age of 47.7 (SD: 11.1) completed the study. The HAQ and DHI were best correlated with clinical activity parameters of RA, such as the Ritchie articular index (RAI), pain (VAS) and erythrocyte sedimentation rate. Radiological scores were best correlated with disease duration. Sex and rheumatoid factor were not significantly correlated with DHI, whereas RF was correlated with functional disability assessed by HAQ. The psychological scales of AIMS correlated well with RAI and swollen joint counts. We found no association between the mean disease duration and scores of functional status. Disability was slightly but not significantly higher in sero $(+)$ than in sero (-) patients. The functional disability scores in patients with long and short disease duration were not significantly different.

Conclusion Self-reporting functional disability questionnaires can provide accurate information about clinical and functional status in a cost-effective way for Turkish RA patients, as for those in other countries. 